\title{
17. NUEVAS APORTACIONES A LA LABOR LIQUENOLÓGICA DE PABLO DE LALLAVE (1777-1833): UN TRABAJO INÉDITO PRESENTADO ANTE LA REAL ACADEMIA MÉDICA DE MADRID*
}

\author{
Raúl RODRÍGUEZ NOZAL \\ Esther DOTOR FERNÁNDEZ
}

La entrada de las teorías liquenológicas del sueco E. Acharius (1757-1819) en nuestro país se produjo gracias a la intervención de los botánicos españoles vinculados a la «Escuela de Cavanilles» (1), S.R. Clemente (1777-1827) y M. Lagasca (1776-1839), y al sacerdote de origen mejicano P. Lallave (1777-1833). Precisamente a este último se debe la primera crítica de conjunto a la obra de E. Acharius, publicada en España en 1820 (2). El contacto del botánico hispano-mejicano con la obra del científico sueco tuvo lugar tras la estancia del primero en París durante 1806, allí trabajo junto con A.J. Bonpland (1773-1858) y A.P. De Candolle (1778-1841) quienes le presentaron ante la Sociedad Filomática, donde ofrecería dos memorias de corte liquenológico, a las cuales, lamentablemente, no hemos podido tener acceso (3).

Análogamente a como ocurriera con su presentación en la Sociedad Filomática de París, un año más tarde, P. Lallave también disertaría ante la Real Academia de Medicina de Madrid con objeto de optar a una plaza de Académico en este Centro científico. El trabajo elegido para esta ocasión sería el titulado: «Sobre algunas especies nuevas de lichenes», una memoria inédita que pasa por ser una de las primeras aportaciones escritas a la liquenología española.

Este manuscrito, sin fechar pero muy probablemente de 1807, compuesto por seis cuadernillos de dos hojas cada uno y una guarda donde aparece reseñado el título, se conserva en el Archivo de la Real Academia de Medicina de Madrid, carpeta [6] (serie catálogo), documento 27a. E1 trabajo comienza con algunas consideraciones generales acerca de los líquenes: la «simplicidad de su organización», «la reserva misteriosa con q. se multiplican, el rigor de la estacion en q. florecen», "la calidad de los sitios en q. viven, y la poca vistosidad del colorido y formas con q. se presentan», para continuar con algunas apreciaciones sobre la importancia de los líquenes como organismos productores de oxígeno; finaliza con la descripción de seis especies del género Parmelia Ach., incluidas, a criterio de P. Lallave, en la sección Canalicularia Ach., a las que designa como: Canalicularia luxurians, Canalicularia mollis, Canalicularia echinata, Canalicularia candida, Canalicularia capillata y Canalicularia hamata. Las descripciones, que permanecen inéditas, no fueron publicadas por ninguno de sus contemporáneos (4).

La memoria de P. Lallave fue sometida a la censura de la Real Academia de Medicina de Madrid. Los académicos elegidos para juzgarla fueron J. Pavón (1754-1840) y M. Sessé (1751-1808), ambos elogiaron el trabajo, a su juicio, un fiel reflejo de la investigación de $P$. Lallave en esta nueva rama de la Botánica y una excelente aportación taxonómica al género Parmelia Ach.:

«Las canicularias [sic], es una de las

\footnotetext{
* Realizado con cargo al Proyecto de Investigación PR179/91-3491, financiado por la Universidad Complutense de Madrid.
} 
criptogamas que intimidan à los Botanicos consumados, y à los mismos maestros de la Ciencia; no tanto por la asombrosa multitud de individuos que la componen como por la mucha semejanza conq ${ }^{\mathrm{e}}$. se presentan los de una misma [ilegible], y la pequeñez, o finura de los caracteres $\mathrm{q}^{\mathrm{e}}$. los distinguen» (5).

\section{NOTAS}

1. Sobre la «Escuela Cavanilles» cf. A. González Bueno. Llull, 11: 51-74. 1988.

2. P. Lallave. Periódico de la Sociedad MédicoQuirúrgica de Cádiz, 1: 99-117. 1820.
3. A. González Bueno \& V.J. Rico. Acta Botánica Malacitana, 16(1): 141-148. 1991.

4. A. Zahlbruckner. Catalogus lichenum universalis. 9 vol. Leipzig, 1922-1934.

5. Informe conjunto emitido por J. Pavón y M. Sessé. Madrid, 14-V-1807. Archivo de la Real Academia de Medicina de Madrid, carpeta 22, documento 1382.

Aceptado para su publicación en Febrero de 1994

Dirección de los autores. Departamento de Farmacia y Tecnología Farmacéutica (Cátedra de Historia de la Farmacia), Facultad de Farmacia, Universidad Complutense de Madrid, 28040-Madrid.

\title{
18. LOS MANUSCRITOS DE FRANCISCO NOROÑA (ca. 1748-1788) CON- SERVADOS EN EL MUSEUM D'HISTOIRE NATURELLE DE PARIS*
}

\author{
Susana PINAR GARCÍA
}

Francisco Noroña (ca. 1748-1788) nació en Sevilla (1), donde cursó estudios de Medicina, trasladándose más tarde a París y Londres para ampliar sus conocimientos de Física, Química, Botánica e Historia Natural. Entre 1784 y 1788 viajó por la costa oriental de la India y Ceilán. Posteriormente, durante su estancia en Filipinas (1784-1786), realizó algunos estudios sobre producciones naturales (canela y seda) (2) y un estudio de historia natural .de las Islas, hoy en paradero desconocido; en 1786 herborizó el interior occidental de Batavia
(Jakarta, Java), convirtiéndose en el primer botánico al que el Gobierno holandés permitió el acceso a las tierras interiores de Java, hasta entonces sólo herborizada en algunos puntos de la costa y los alrededores de Batavia; la siguiente escala de su viaje fue Isla Mauricio, donde visitó el Jardín de Pamplemousses, posteriormente se trasladó a la Isla de Madagascar; desafortunadamente, estos últimos capítulos del diario de viaje de F. Noroña se encuentran incompletos por su prematura muerte, acaecida en Isla Mauricio, el 12 de junio de 1788, a

\footnotetext{
* Este trabajo se incluye en el proyecto PB91-0068.
} 